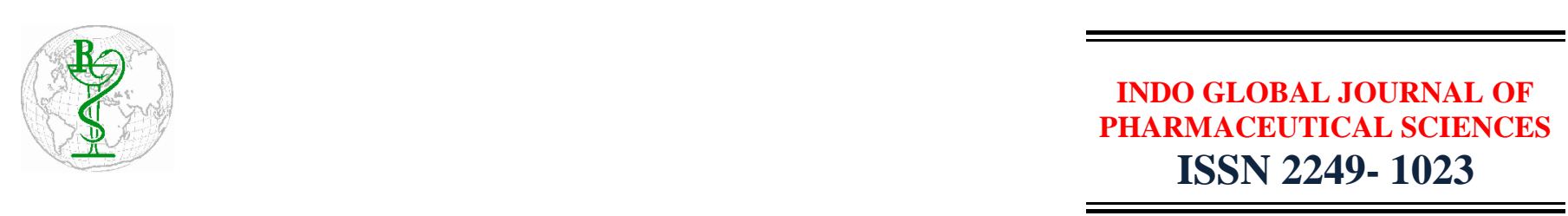

\title{
Research Initiatives in Supply Chain System for Drug Delivery and Management System
}

\author{
Praveen Srivastava, A S Cheema * \\ CDAC, Noida, India
}

Address for Correspondence: A S Cheema; ascheema@cdac.in

\begin{abstract}
Government of India has initiated several programs to provide health benefit to the ultimate beneficiary who is a common man of India. The major thrust is to provide the benefit in transparent manner without any pilferage. Free Drug Distribution is one of thrust area for all the State Government and Government of India. Information Technology enablement of the scheme was the only option to meet the objective of the Government. The ulterior motive of the research work is to gradually transform a lucid and intelligible Inventory Management System into a well-organized and competent Supply Chain Management of Drugs To commence with, the system is a complete blend of standard procedures offered by GS1 Standards and MDDS (Metadata and Data Standards), further grouped with various enhanced processes like Digital Signature in PO/Acceptance Certificate, Categorization of Drugs as per CIMS, GFR (General Financial Rule) for defining the rules for procuring the drugs and many more. The paper also focuses on various innovations like Desktop application, which grips the complete application without using internet connection, that uproots and upgrades the system into a more competent application in rural areas. The research adopted various mathematical analysis and algorithms to manage inventory and predict future requirement of drugs. The paper even illustrates a staple and customary procedure to not only manage Drug Inventory, but create a benchmark for same. () 2014 iGlobal Research and Publishing Foundation. All rights reserved.
\end{abstract}

Conference Proceedings: International Conference on Life Sciences, Informatics, Food and Environment; August 29- 30, 2014

Indo Global Journal of Pharmaceutical Sciences( ISSN 22491023 ; CODEN- IGJPAI; NLM ID: 101610675) indexed and abstracted in EMBASE(Elsevier), SCIRUS(Elsevier),CABI, CAB Abstracts, Chemical Abstract Services(CAS), American Chemical Society(ACS), Index Copernicus, EBSCO, DOAJ, Google Scholar and many more. For further details, visit 